\title{
Prevalence of Canine Otitis Externa, Etiology and Clinical Practice in and around Durg District of Chhattisgarh State, India
}

\author{
Roy Manju ${ }^{1 *}$, Kashyap Roshan ${ }^{2}$ and Roy Suhsovan ${ }^{2}$ \\ ${ }^{I}$ Veterinary physiology and Biochemistry department, College of Veterinary Science \& A.H., \\ Anjora, Durg (Chhattisgarh) India \\ ${ }^{2}$ Veterinary Medicine Department, College of Veterinary Science \& A.H., Anjora, Durg \\ (Chhattisgarh) India \\ *Corresponding author
}

A B S T R A C T

Keywords

Prevalence, Canine,

Ear, Bacteria,

Antibiotic

Article Info

Accepted:

04 February 2018

Available Online:

10 March 2018
The present study was conducted to record the prevalence percentage (\%), suitable cytological diagnostic procedure followed by isolation of causative agent and effective therapies against otitis externa. A total of $281 \mathrm{dogs}$ irrespective of age, breed and sex from various sources i.e. dogs presented to T.V.C.C., Anjora and different Government Veterinary Hospitals in and around Durg were included in the present study. Based on clinical examination, $51 \mathrm{dogs}$ were found to be positive for otitis externa. Out of these 51 dogs, 24 dogs suffering from otitis externa. The prevalence of otitis externa in the present study was $18.14 \%$. Age wise prevalence revealed that dogs of age $>5$ years were mostly affected as compared to all other age groups. Breed wise prevalence revealed that German shepherd was most commonly affected breed. Animals administered with injectable Amoxycillin- Sulbactum along with topical application of salicylic acid based ear cleanser showed best results

\section{Introduction}

Otitis externa is one of the most common and multifactorial disorders accounting for up to 10 to $20 \%$ of consultations in canine practice (Senthil et al., 2010). The etiological factors of otitis externa can be categorized as predisposing factors, primary causes, perpetuating factors and secondary causes with predisposing factors. Primary factors are those diseases of the skin that also have a direct effect on the skin that lines the ear canal. parasites, foreign bodies, hypothyroidism and keratinizing diseases frequently result in ear disease Predisposing factors are those things that directly change the micro climate in the ear canal (Paterson, 2016).

The microclimate changes include increased temperature from inflammation, increased humidity from poor ventilation and stenosis, and changes in the composition of the cerumen. Certain breeds like Cockers, Labradors and Springer shave more cerumen glands that favor yeast growth. Humid 
environments and excessive moisture in the ears from swimming or bathing promote bacterial growth. Excessive trauma to the ear canal resulting from exuberant ear cleaning or trauma from instruments used in the ear canal may allow bacterial colonization (Balappanavar and Vasant 2013).

Clinical signs of otitis externa include head shaking, ear scratching and pain on palpation of ear. An otic discharge that may be malodorous is often present. In acute cases, inner ear pinna and ear canal are usually erythematous and swollen. Pinnal alopecia, excoriations and crusts are also noticed. Stenosis, accompanied by fibrosis and papular to nodular hyperplasia of the walls of the canal, allows further microbial growth that perpetuates disease (Huang and others 2009). Diagnosis of otitis externa can be done by otic examination and cytology of otic discharge. Otic examination by video-otoscope provides a rapid means of diagnosing foreign bodies, Otodectes mites, tumors, exudates, ruptured tympanum and excess hairs within the ear canal (Hernandez- Escareno et al., 2012).

Though not a life threatening ailment, it can be a frustrating disease for canine patients and their owners. Hence in the present research work, cytological examination is performed to identify the target organisms,

\section{Materials and Methods}

The dogs brought for treatment to the TVCC and various Government Veterinary hospitals in and around Durg district of Chhattisgarh state were studied period of one year from July, 2016, to June, 2017. Ear exudates samples were obtained by inserting sterile swabs to the junction of vertical and horizontal external ear canal. Dogs were clinically examined for their normal appearance and diseased condition. Patient's data, owner's complaint and clinical signs of disease were recorded. Restlessness and frequent ear itching were accompanied by ottorrhoea with discharge varying from yellowish brown to white purulent in colour. The most common clinical signs observed included head shaking, ear scratching, pain on palpation of the ear, ear rubbing, and tilting of head to one side.

\section{Sample collection}

Samples were collected from the dogs showing clinical signs of otitis externa. Following aseptic precautions, after swabbing the sites with 70 per cent ethanol and allowing it to air dry, the otic exudates were collected from dog's upper portion of vertical canal using sterile cotton swabs also from each clinical case presented with otitis externa at the hospital for cytological evaluation and bacteriological examination as per the method described by Wilkinson and Harvey (1994).

\section{Cytological examination}

Swabs collected were gently rolled onto a microscopic slide, air dried, stained with New Methylene blue and examined under oil immersion objective $(100 \mathrm{x})$ of the microscope which allowed rapid assessment for the presence of cocci, rods and Malassezia (Mactaggart, 2008).

\section{Clinical practice}

All animals affected with otitis externa were treated with injectable Amoxycillin and sulbactum combination once daily for 5 days along with cleaning of ear with salicylic acid based ear cleanser on alternate days.

\section{Results and Discussion}

During the period under study, screening of 281 cases presented at Teaching Veterinary Clinical Complex, College of Veterinary 
Science and Animal Husbandry, Anjora and various Government Veterinary Hospitals in and around Durg revealed that clinical cases of otitis externa were present in 51 dogs with an overall prevalence of $18.14 \%$. The findings of present study were in close agreement with those stated by Scott et al., (2001) who reported the prevalence rate of otitis externa as 10 to $20 \%$ respectively.

Age wise prevalence of otitis externa in dogs in and around Durg

The age wise prevalence was recorded (Table 1) in different age group of animals i.e., upto 1 year, 1 to 3 years, 3 to 5 years, 5 years and more prevalence was recorded in the age group of 5 years and above (old dog) might be due to immune suppression, increase sebum production and poor management practices.

The highest prevalence $(45.10 \%)$, of otitis externa was seen in the age group of 5years and above. The findings of present study are in agreement with the findings of Agnihotri et al., (2014) who have also reported maximum prevalence of otitis externa in dogs of age between 5 to 8 years followed by dogs between 3 to 6 years of age. However, Zur et al., (2011) observed no age predilection in dogs suffering from otitis externa.

\section{Breed wise prevalence}

The highest occurrence of otitis externa as observed in German shepherd (31.37\%) followed by Labrador retriever (19.6\%), Spitz (17.64\%), Rottweiler (11.76\%), Pug (5.88\%), Saint Bernard (3.92\%), Doberman (1.96\%), Dalmatian (1.96\%), Cocker spaniel (1.96\%) and others $(3.92 \%)$ respectively. Kumar et al., (2002) stated that German shepherd was the most frequently affected breed followed by Labrador. Similarly, Nair (2004) also reported 34 German shepherd dogs suffering from otitis externa, followed by Mongrel (11), and Spitz
(8). Dogs with long ears are more susceptible. Excessive moisture caused by swimming or abrasive and improper ear cleaning lead to otiits externa. Similarly, August (1988) attributed greater vulnerability of German shepherd breed to otitis on account of hyperactivity of cerumen producing glands.

\section{Sex wise prevalence}

In the present study, sex wise prevalence of otitis externa was recorded to be relatively among more the males $(52.95 \%)$ as compared to females $(47.05 \%)$. The findings are in partial agreement with Nardoni et al., (2004) who have stated that there are no significant differences in terms of sex in relation to occurrence of otitis externa in dogs. Many dog owners usually prefer male dogs as companion animals and it is quite possible that the higher prevalence recorded in male dogs might be primarily related to this selective preference of the pet lovers.

It is possible that androgen hormones tend to increase sebum production which appears to be predisposing factors to flare up latent infection. The findings of the present study are in accordance with the reports of Agnihotri et al., (2014) who have reported higher prevalence of otitis externa in male dogs $(68.71 \%)$ than that female $\operatorname{dog}(31.29 \%)$.

\section{Season wise prevalence}

Present study was recorded the variation in prevalence of otitis externa in dog in different season. The seasons were summer (MarchJune), Rainy (July-October), and winter (November- February).The findings revealed that the seasonal variation has influence on occurrence of dog otitis externa in Durg district of Chhattisgarh state. The present study indicates that the prevalence of otitis externa was reported to be highest during summer season $(41.18 \%$ ) (Table 2 ). 
Table.1 Age wise prevalence of otitis externa in dogs in and around Durg

\begin{tabular}{|l|c|c|c|}
\hline $\begin{array}{l}\text { Age No. of dogs } \\
\text { Examined }\end{array}$ & $\begin{array}{c}\text { No. of dogs } \\
\text { Examined }\end{array}$ & $\begin{array}{c}\text { No. of positive } \\
\text { Cases }(\mathbf{n = 5 1 )}\end{array}$ & $\begin{array}{c}\text { Prevalence } \\
(\boldsymbol{\%})\end{array}$ \\
\hline Up to 1 year & 55 & 3 & 5.88 \\
\hline 1 to 3 years & 70 & 9 & 17.65 \\
\hline 3 to 5years & 75 & 16 & 31.37 \\
\hline 5 years and above & 81 & 23 & 45.10 \\
\hline
\end{tabular}

Table.2 Season wise prevalence of otitis in dogs in and around durg

\begin{tabular}{|l|c|c|}
\hline Season & No. of Positive cases $(\mathbf{n = 5 1 )}$ & Prevalence \% \\
\hline Summer & 21 & 41.18 \\
\hline Rainy & 17 & 33.33 \\
\hline Winter & 13 & 25.49 \\
\hline
\end{tabular}

Table.3 Distribution of microorganism in otitis externa by cytological

\begin{tabular}{|l|l|}
\hline Types of microorganism & Direct impression smear \\
\hline Coci & $16(76.1 \%)$ \\
\hline Bacilli & $10(47.6 \%)$ \\
\hline Yeast & $4(19.0 \%)$ \\
\hline
\end{tabular}

In the present study, the prevalence of otitis externa in dogs was recorded to be highest in summer followed by rainy season while lowest prevalence of otitis externa was recorded in winter season. These findings are in concordance with findings of Balappanavar and Vasant (2013) and Kumar et al., (2011) who stated that the incidence of otitis externa among dogs is highest in summer season as compared to other seasons. Hayes et al., (1987) have reported that the incidence of otitis externa does seems to fluctuate in response to climatic variation and prevalence observed more in late summer with high humidity result in the development of ideal environment for the growth of bacteria and yeast (Table 3 ).

In the present investigation, findings related to diagnosis of canine otitis externa using tape impression smear $(68.62 \%)$ are in accordance with findings of Curtis (2001). Bacterial otitis were diagnosed in 4 out of 50 cases (4\%). The exudates from auditive canal had a purulent characteristic. The cytological exam showed a bacterial polymorphous flora consisting in cocci and bacilli. In severe cases phagocitic cells were seen, especially neutrophils that cleared up the bacteria. In these cases, bacteriologic examination of the secretion was made, and the results showed G+ (Staphylococcus spp., Streptococcus spp) and G-(Pseudomonas spp) bacteria (Mircean et al., 2008). On the basis of cytological examination by direct impression smear method it was concluded that prevalence percentage of otitis externa was more due to cocci followed by Bacilli and yeast.

\section{Therapeutic measures against otitis} externa

The clinical recoveries in otitis externa affected canine patients were assessed on the 
basis of improvement in clinical signs and restoration of the altered haematobiochemical parameters following treatment. The clinical recovery was noticed in all groups but earlier and best response to therapy was recorded in the animals with administration of amoxicillin and sulbactum combination Injectable Amoxycillin and sulbactum combination@ @-10 mg/kg body weight intramuscular once daily for 5 days along with tropical application of ear cleanser containing salicylic acid.

The topical application of salicylic acid based ear cleanser for clinical management of otitis externa in dogs has been advocated by various workers (Pushpa et al., 2015, Singh, 2016). In addition to antibacterial activity, salicylic acid has also been proved to exert anti yeast activity for management of different dermatological conditions including otitis externa

\section{References}

Agnihotri, D., Sharma, A. and Khurana, R. 2014. XXXII Annual Convention of ISVM and International Symposium on the 21st Centuary Road map for Veterinary Practice, Education and research in India and Developing Countries. 6:21-91.

August, J.R. 1988. Diseases of the ear canal. Veterinary Clinics of North American Small Animal Practice. 18(4): 731-742.

Balappanavar, B.R. and Vasanth, M.S. 2013. Clinico-diagnostic and therapeutic management of canine malasseziosis. Intas Polivet. 14(2): 353-358.

Curtis, C.F. (2001). Diagnostic techniques and sample collection. Clinical Techniques in Small animal Practice. 16 (4): 199-206.

Hayes, H.M., Pickle, L.W. and Wilson, G.P. 1987. Effects of ear type and weather on the hospital prevalence of canine otitis externa. Research in Veterinary Science. 42:294-298.

Hernandez, E.J.J, Sandoval, C.F., Salinas, J.A., Riojas, V.M., Picon, F., Davalos, A.G. and Sanchez, J.M. 2012. Malassezia pachydermatis in dogs with external otitis from Monterrey, Nuevo Leon, Mexico. African Journal of Microbiology Research. 6(10): 24432448.

Huang, H. P., Little, C. J. and Mcneil, P. E. 2009 Histological changes in the external ear canal of dogs with otitis externa. Veterinary Dermatology. 20, $422-428$

Kumar, A., Singh, K. and Sharma, A. 2002. Prevalence of Malassezia pachydermatis and other organisms in healthy and infected dogs ears. Journal of Israel Veterinary Medical Association. 57 (4): 399-401.

Kumar, K.S., Selvaraj, P., Vairamuthu, S., Nagarajan, B., Nambi, A.P. and Prataban, S. 2011. Survey of fungal isolates from canine mycotic dermatitis in Chennai. Tamil Nadu Journal of Veterinary and Animal sciences. 7(1):48-50.

Mactaggart, D. 2008. Assessment and management of chronic ear disease. In Practice. 30:450-458.

Mircean, V., Mircean, M., Gavrea, R. and Cozma., V. 2008. Epidemiological aspects of otitis externa in dogs. Lucrări Tiinfifice Medicină Veterinară Vol. Xli, 2008, Timisora

Mircean, V., Mircean, M., Gavrea, R. and Cozma., V. 2008. Epidemiological aspects of otitis externa in dogs. Lucrări Tiinłifice Medicină Veterinară Vol. Xli, 2008, Timisora.

Nair, S. 2004. Studies on clinicoetiopathology and therapeutic management of various canine dermatoses. M.V.Sc. Thesis submitted 
to Anand Agricultural University, Anand, Gujarat.

Nardoni, S., Mancianti, F., Corazza, M., and Rum, A. 2004. Occurrence of Malassezia species in healthy and dermatologically diseased dogs. Mycopathologia. 157(4): 383-388.

Paterson, S. 2016.Topical ear treatmentoptions, indications and limitations of current therapy. Journal of Small Animal Practice. 7:67-75.

Pushpa, Y., Anand, R.K. and Anand, G. 2015. Diagnosis and management of pseudomonas associated canine otitis. Intas Polivet 16(2): 330-332.

Scott, D.W., Miller, W.H. and Griffin, C.E. 2001. Diseases of the eyelids, claws, anal sacs and ears. In Small Animal
Dermatology, 6th edn, Philadelphia, W B Saunders, PP: 71 - 1235

Senthil, K.K., Selvaraj, P., Vairamuthu, S., Mala, S. and Kadiresan, D. 2010. Antibiogram patterns of microbes isolated from otitis externa of dogs. Tamil Nadu Journal Veterinary and Animal Sciences. 6 (3):145-147.

Singh, R. 2016. A study on Surgicotherapeutic management of various dermatological emergencies in dogs M.V.Sc. thesis submitted to RAJUVAS Bikaner.

Wilkinson, G.T. and Harvey, R.G. 1994. Colour Atlas of Small Animal Dermatology - A Guide to Diagnosis, $2^{\text {nd }}$ edn. Mosby-Wolfe Bar.

\section{How to cite this article:}

Roy Manju, Kashyap Roshan and Roy Suhsovan. 2018. Prevalence of Canine Otitis Externa, Etiology and Clinical Practice in and around Durg District of Chhattisgarh State, India. Int.J.Curr.Microbiol.App.Sci. 7(03): 269-274. doi: https://doi.org/10.20546/ijcmas.2018.703.031 